\title{
A high oxidised frying oil content diet is less adipogenic, but induces glucose intolerance in rodents
}

\author{
Pei-Min Chao ${ }^{1}$, Hui-Ling Huang ${ }^{1}$, Chun-Huei Liao ${ }^{1}$, Shiau-Ting Huang ${ }^{1}$ and Ching-jang Huang ${ }^{2,3}$ \\ ${ }^{1}$ Department and Institute of Nutrition, China Medical University, Taichung, Taiwan \\ ${ }^{2}$ Department of Biochemical Science and Technology Institute of Microbiology and Biochemistry, College of Life Science, \\ National Taiwan University, Taipei, Taiwan \\ ${ }^{3}$ Division of Nutritional Science, Institute of Microbiology and Biochemistry, College of Life Science, National Taiwan University, \\ Taipei, Taiwan
}

(Received 6 November 2006 - Revised 18 December 2006 - Accepted 8 January 2007)

\begin{abstract}
Oxidised frying oil (OFO) and fish oil have been shown to be peroxisome proliferator-activated receptor (PPAR) $\alpha$ activators and their ingestion results in pleotropic peroxisome proliferator responses in rats. To examine the effect of dietary OFO on adiposity, four groups of weanling Sprague-Dawley rats were fed isoenergetically with, respectively, a low fat basal diet containing $5 \mathrm{~g} / 100 \mathrm{~g}$ of fresh soybean oil (LSB) or a high fat diet containing $20 \mathrm{~g} / 100 \mathrm{~g}$ of fresh soybean oil (HSB), OFO (HO) or fish oil (HF). The tissue mass, cell size and lipid/DNA ratio in the retroperitoneal fat pad and serum leptin levels were lowest in the HO group $(P<0 \cdot 05)$, indicating that dietary OFO has a greater anti-adipogenic action than dietary fish oil. However, a tendency to hyperglycaemia was observed in the HO group $(P=0.0528)$. To examine the effect of dietary OFO on glucose tolerance, three groups of rats and three groups of mice were fed, respectively, the LSB, HSB or HO diet, and an oral glucose tolerance test was performed. After oral glucose load, the area under the curve for blood glucose $\left(\mathrm{AUC}_{\mathrm{glu}}\right)$ over $2 \mathrm{~h}$ was significantly higher, and that for serum insulin $\left(\mathrm{AUC}_{\text {ins }}\right)$ over $90 \mathrm{~min}$ was significantly lower, in the $\mathrm{HO}$ group than in the other two groups $(P<0 \cdot 05)$. These results demonstrate that, in rats and mice, a high OFO diet is less adipogenic, but induces glucose intolerance.
\end{abstract}

Oxidised frying oil: Anti-adiposity: Glucose intolerance: Rodents

Obesity is known to be associated with type 2 diabetes mellitus (T2DM). Reducing weight or adiposity (especially visceral fat) is often emphasised as a pivotal component of guidelines for risk reduction (Despres, 2006). However, as well as in type 1 diabetes mellitus (T1DM) patients, lean cases are also seen in T2DM, especially in developing countries, such as India, and China, and in Africa (Das, 1999). In India, it has been reported that a quarter of T2DM patients have a BMI less than 19 and are not malnourished (Das, 1999). Little is known about the aetiology of this lean-type diabetes mellitus.

Dietary oxidised frying oil (OFO) and fish oil have been shown to be peroxisome proliferator-activated receptor $\alpha$ $(\operatorname{PPAR} \alpha)$ activators (Chao et al. 2001, 2005; Sulzle et al. 2004). When rats are fed with a fish oil- or OFO-rich diet, the pleotropic effects of peroxisome proliferators (PP), including hepatomegaly, peroxisome proliferation, reduction in liver (and serum) lipids and upregulation of hepatic acyl-CoA oxidase (ACO) and cytochrome P450 4A (CYP4A) gene expression are observed (Chao et al. 2005). Based on the extent of peroxisome proliferation and $\mathrm{ACO}$ and CYP4A induction, dietary OFO is regarded as being more potent than fish oil in activating the $\operatorname{PPAR} \alpha$ signalling pathway (Chao et al. 2005).

Reduction in adiposity is another frequently reported PP response (Storlien et al. 1987; Mancini et al. 2001; Ye et al. 2001; Xie et al. 2002). Among the beneficial effects of fish oil, the reduction in adiposity and amelioration of insulin resistance have been well characterised (Parrish et al. 1990; Baillie et al. 1999). However, the effects of OFO consumption on adiposity and glucose tolerance have not been reported. In this study, Experiment 1 was designed to evaluate the effect of an OFO diet on adiposity, and to compare this with the effect of a fish oil diet. The objective of Experiment 2 was to determine the glucose tolerance of rodents fed a high OFO diet. In accordance with previously reported PP responses, the results showed that OFO was a more potent anti-adiposity agent than fish oil. Unexpectedly, the reduction in fat cell hypertrophy in OFO-fed animals was associated with impaired glucose tolerance, as shown by oral glucose tolerance tests (OGTT).

Abbreviations: ACO, acyl CoA oxidase; $\mathrm{AUC}_{\mathrm{glu}}$, area under the curve for glucose; $\mathrm{AUC}_{\mathrm{ins}}$, area under the curve for insulin; CLA, conjugated linoleic acid; CYP4A, cytochrome P450 4A; OFO, oxidised frying oil; OGTT, oral glucose tolerance test; PP, peroxisome proliferator; PPAR $\alpha$, peroxisome proliferator-activated receptor $\alpha$; T1DM, type 1 diabetes mellitus; T2DM, type 2 diabetes mellitus.

* Corresponding author: Dr Pei-Min Chao, fax +886 (0) 4 22062891, email pmchao@mail.cmu.edu.tw 


\section{Materials and methods}

\section{Preparation of $\mathrm{OFO}$}

The OFO was prepared by simulating deep-frying procedure as described previously (Huang et al. 1988). Briefly, $3 \mathrm{~kg}$ of soybean oil (President, Tainan, Taiwan) was poured into a cast iron wok ( $40 \mathrm{~cm}$ internal diameter, $11 \mathrm{~cm}$ central depth) and heated on a gas stove that was adjusted to maintain the oil temperature at $205 \pm 5^{\circ} \mathrm{C}$. Wheat flour dough sheets $(10 \times 4.5 \times 0.15 \mathrm{~cm})$ were fried in the oil, one at a time; a total of about $2 \mathrm{~kg}$ dough per day was used. The frying lasted for $6 \mathrm{~h} / \mathrm{d}$ and was repeated successively for $4 \mathrm{~d}$. After removing the dregs in the oil, the final yield was about $50 \%$. The extent of oxidation was evaluated by acid value and conjugated diene $(1.0 \mathrm{mg} \mathrm{KOH} / \mathrm{g}$ and $4260 \mathrm{OD} / \mathrm{g})$, which was almost equivalent to our previously reported data (Chao et al. 2001).

\section{Animals and diets}

Male weanling Sprague-Dawley rats weighing 50-70 g and 7-week-old male C57BL/6J mice were purchased from the Laboratory Animal Center of the National Science Council (Taipei, Taiwan). All animals were housed individually in stainless steel wire cages in a room maintained at $23 \pm 2{ }^{\circ} \mathrm{C}$, with a controlled $12 \mathrm{~h}$ light:dark cycle and free access to tap water. The protocols for animal care and handling were approved by the Institutional Animal Care and Use Committee (IACUC) of the China Medical University.

The compositions of the four test diets are shown in Table 1, the amounts of casein and the vitamin and mineral mixtures in the three high fat diets being adjusted to ensure that the four diets had an equivalent nutrient/energy ratio.

Table 1. Composition of the test diets used ${ }^{\star} \dagger$

\begin{tabular}{lrrrr}
\hline & LSB & HSB & HO & HF \\
\hline Casein $(\mathrm{g} / \mathrm{kg})$ & 200 & 235 & 235 & 235 \\
Corn starch $(\mathrm{g} / \mathrm{kg})$ & 650 & 448 & 448 & 448 \\
Fresh soybean oil $(\mathrm{g} / \mathrm{kg})$ & 50 & 200 & - & 5 \\
Oxidized frying oil $(\mathrm{g} / \mathrm{kg}) \ddagger$ & - & - & 200 & - \\
Fish oil $(\mathrm{g} / \mathrm{kg})$ & - & - & - & 195 \\
Cellulose $(\mathrm{g} / \mathrm{kg})$ & 50 & 59 & 59 & 59 \\
Mineral mixtures $(\mathrm{g} / \mathrm{kg})$ & 35 & 41 & 41 & 41 \\
Vitamin mixture $(\mathrm{g} / \mathrm{kg})$ & 10 & 12 & 12 & 12 \\
DL-Methionine $(\mathrm{g} / \mathrm{kg})$ & 3 & 3 & 3 & 3 \\
Choline $(\mathrm{g} / \mathrm{kg})$ & 2 & 2 & 2 & 2 \\
Energy density $(\mathrm{MJ} / \mathrm{kg})$ & $16 \cdot 11$ & 18.95 & 18.95 & 18.95 \\
Protein/energy (g/MJ) & 12.40 & 12.40 & 12.40 & 12.40 \\
Vitamins/energy (g/MJ) & 0.62 & 0.62 & 0.62 & 0.62 \\
Minerals/energy (g/MJ) & $2 \cdot 17$ & $2 \cdot 17$ & $2 \cdot 17$ & 2.17 \\
\hline
\end{tabular}

* The four test diets were a low fat diet containing fresh soybean oil (LSB) or high fat diets containing fresh soybean oil $(\mathrm{HSB})$, oxidised frying oil $(\mathrm{HO})$ or fish oil (HF).

†Sources of ingredients: casein, ICN (Aurora, OH, USA); cornstarch, Samyang (Seoul, Korea); cellulose, J. Rettenmaier \& Söhne (Holzmühle, Germany); methionine and choline chloride, Sigma Chemical (St Louis, MO, USA); AIN-76 mineral mixture and AIN-76 vitamin mixture, ICN (Aurora, OH, USA); fresh soybean oil, President Co. (Tainan, Taiwan); and fish oil, TAMA Biochemical Co. (Kamagawa, Japan).

¥Oxidised frying oil was prepared by frying dough sheets in soybean oil (President Co., Tainan, Taiwan) at $205 \pm 5^{\circ} \mathrm{C}$ for $24 \mathrm{~h}$.

\section{Experiment 1. Effect of dietary $O F O$ on adiposity}

Forty weight-matched rats were divided into four groups of ten to receive, respectively, a low fat diet containing $5 \mathrm{~g} /$ $100 \mathrm{~g}$ of fresh soybean oil (LSB) or a high fat diet containing $20 \mathrm{~g} / 100 \mathrm{~g}$ of fresh soybean oil (HSB), OFO (HO) or fish oil (HF) for 6 weeks. Since the OFO-containing diet led to a significantly reduced feed intake, all rats in the LSB, HSB and $\mathrm{HF}$ groups were pair-fed isoenergetically with the HO group of rats, which was the only group fed ad libitum. At the end of week 6 , the rats were killed by carbon dioxide asphyxiation after $10 \mathrm{~h}$ of fasting. White adipose tissue, consisting of the epididymal and retroperitoneal fat, was excised and weighed. A small portion of the epididymal fat and the retroperitoneal fat was fixed to measure adipocyte size, and the remainder was stored at $-20^{\circ} \mathrm{C}$ for lipid and DNA quantification. Serum were obtained by centrifugation $(3000 \mathrm{~g}, 15 \mathrm{~min}$ at $4^{\circ} \mathrm{C}$ ) of tail blood and stored at $-20^{\circ} \mathrm{C}$ for glucose and leptin analysis.

\section{Experiment 2. Effect of dietary $\mathrm{OFO}$ on glucose tolerance}

Thirty rats and thirty mice were each divided into three groups of ten to receive the same LSB, HSB and HO diets for 9 or 5 weeks, respectively. Since, in Experment 1, the anti-adiposity effect of OFO was still seen in rats receiving the same energy intake (Table 2), thus showing that the effect was not due to food intake, all animals in this study were fed ad libitum. An OGTT was performed on rats fed the experimental diets for 0,3 or 9 weeks and on mice fed the diets for 4 weeks. On the test days, after overnight food deprivation, blood was collected from the tail before $(0 \mathrm{~min})$, and at the indicated time points after, oral gavage with a $2.5 \mathrm{M}$-glucose solution $(1.5 \mathrm{~g} / \mathrm{kg}$ body weight). In the mouse study, serum insulin levels were determined in addition to blood glucose levels by OGTT. The insulin levels in both fasted and non-fasted states were also determined at the end of week 5. For the measurement of insulin in the non-fasted state, mice were fasted overnight, then $1 \mathrm{~g}$ of feed per mouse was provided at 07.00 hours and tail blood was collected between 10.00 and 11.00 hours. Food containers were almost empty at the time of blood collection. At the end of the experimental period, the fasted animals were killed, the tissues excised and weighed, and liver and serum lipids determined as described previously (Chao et al. 2001).

\section{Glucose, insulin and leptin analyses}

Serum glucose was measured by the glucose oxidase method (Randox Laboratories, Crumlin, UK), serum being prepared within $30 \mathrm{~min}$ and analysed within $24 \mathrm{~h}$ of collection. In the OGTT, whole blood glucose levels were measured using a MediSense Optium glucometer (Abbott Laboratories, Worcester, MA, USA). Serum leptin (R\&D, Minneapolis, MN, USA) and serum insulin (Linco, St Charles, MO, USA) were measured by enzyme-linked immunosorbent assay.

\section{Measurement of adipose cell size}

The method for measuring adipose cell size was a slight modification of that of Hirsch \& Gallian (1968). Briefly, fat slices 
Table 2. Body weight gain, relative adipose tissue weights, and serum glucose and leptin levels in rats fed a low fat diet containing $5 \mathrm{~g} / 100 \mathrm{~g}$ of fresh soybean oil (LSB) or a high fat diet containing $20 \mathrm{~g} / 100 \mathrm{~g}$ of fresh soybean oil (HSB), oxidised frying oil (HO) or fish oil (HF) (Experiment 1)*

(Mean values and standard deviations for ten animals)

\begin{tabular}{|c|c|c|c|c|c|c|c|c|}
\hline & \multicolumn{2}{|c|}{ LSB } & \multicolumn{2}{|c|}{ HSB } & \multicolumn{2}{|c|}{$\mathrm{HO}$} & \multicolumn{2}{|c|}{$\mathrm{HF}$} \\
\hline & Mean & SD & Mean & SD & Mean & SD & Mean & SD \\
\hline Initial body weight (g) & 63.4 & $6 \cdot 6$ & 63.8 & $7 \cdot 2$ & $65 \cdot 7$ & 5.5 & 64.8 & 5.5 \\
\hline Final body weight $(\mathrm{g})$ & $222^{d}$ & 18 & $288^{\mathrm{b}}$ & 30 & $249^{c}$ & 14 & $319^{\mathrm{a}}$ & 29 \\
\hline Body weight gain $(\mathrm{g} / 40 \mathrm{~d})$ & $159^{d}$ & 15 & $225^{\mathrm{b}}$ & 24 & $183^{\mathrm{c}}$ & 15 & $254^{\mathrm{a}}$ & 27 \\
\hline Energy intake $(\mathrm{kJ} / \mathrm{d})$ & 370 & 5 & 362 & 15 & 369 & 34 & 366 & 37 \\
\hline Relative epididymal fat weight (\%)† & $1.05^{\mathrm{b}}$ & 0.27 & $1.35^{\mathrm{a}}$ & 0.16 & $1 \cdot 14^{\mathrm{b}}$ & 0.22 & $1.02^{\mathrm{b}}$ & 0.26 \\
\hline Relative retroperitoneal fat weight $(\%) \dagger$ & $1 \cdot 24^{\mathrm{b}}$ & 0.20 & $1.53^{\mathrm{a}}$ & 0.37 & $0.62^{\mathrm{c}}$ & 0.31 & $1 \cdot 14^{\mathrm{b}}$ & 0.33 \\
\hline Serum glucose $(\mathrm{mmol} / \mathrm{l})$ & $6 \cdot 7^{\mathrm{b}}$ & 0.9 & $6 \cdot 5^{\mathrm{b}}$ & 1.3 & $8 \cdot 0^{\mathrm{a}}$ & 1.5 & $6 \cdot 9^{\mathrm{ab}}$ & $1 \cdot 2$ \\
\hline Serum leptin $(\mu \mathrm{g} / \mathrm{l})$ & $1.4^{\mathrm{ab}}$ & 0.9 & $1 \cdot 7^{\mathrm{a}}$ & $1 \cdot 2$ & $0.7^{\mathrm{b}}$ & 0.3 & $1 \cdot 3^{\mathrm{ab}}$ & $1 \cdot 2$ \\
\hline
\end{tabular}

*The significance of differences between the four groups was analysed by one-way ANOVA and Duncan's multiple range test. Mean values within a row with different superscript letters are significantly different $(P<0.05)$.

$\dagger$ The relative tissue weight $(\%)$ is the tissue weight divided by the body weight $\times 100 \%$.

$(<200 \mathrm{mg})$ cut from the epididymal and retroperitoneal fat were rinsed with saline at $37^{\circ} \mathrm{C}$, then fixed in $2 \%$ osmium tetroxide in collidine- $\mathrm{HCl}$ buffer $(\mathrm{pH} \mathrm{7.4)}$ at room temperature. After $3 \mathrm{~d}$, the fixation solution was removed and replaced by saline for $24 \mathrm{~h}$, then the saline was removed and $10 \mathrm{ml}$ of $8 \mathrm{M}$-urea added for $24 \mathrm{~h}$ with occasional swirling to liberate the cells. Finally, the adipocytes were isolated by successive filtering through nylon mesh screens with diameters of 235 and $10 \mu \mathrm{m}$, and washed with $0.01 \%$ Triton X-100 in distilled water. The numbers of adipocytes with different diameter ranges were counted using a Coulter counter (Coulter Corporation, Miami, FL, USA).

\section{Quantification of lipid and DNA in adipose tissue}

For the analysis of adipose lipid content, total lipid was extracted from the epididymal and retroperitoneal fat using the Folch method (Folch et al. 1957). The total lipid content of the adipose tissue samples was determined by weighing after complete removal of the organic solvent. As the DNA content of each cell is constant, the DNA content of the epididymal and retroperitoneal fat was measured according to Saha et al. (1994) as an indicator of adipose cell numbers. The adipose tissue was homogenised in PSE buffer (50 mM-sodium phosphate, $\mathrm{pH} 7 \cdot 4$, containing $2 \mathrm{M}-\mathrm{NaCl}$ and 1-mM EDTA) and the lipids removed by acetone. An aliquot of the fat-free homogenate was then mixed with $1 \mu \mathrm{g} / \mathrm{ml}$ Hoechst 33258 (Sigma Chemical Co., St Louis, MO, USA) and DNA was analysed by fluorospectrometry using excitation at $365 \mathrm{~nm}$ and emission at $460 \mathrm{~nm}$ (Hitachi F2000, Japan). Calf thymus DNA (Sigma Chemical Co.) at different concentrations in PSE was used as the standard.

\section{Statistical analysis}

Data are expressed as the mean and SD for the ten rats or mice in each group. The significance of differences between groups was analysed statistically by one-way ANOVA and Duncan's multiple range tests. The data were transformed to log values for the statistical analysis if the variances were not homogeneous. The general linear model of the SAS package (SAS institute, Cary, NC, USA) was used for both statistical analyses, and differences were considered significant at $P<0 \cdot 05$.

\section{Results}

Body weight and adipose tissue weight

Despite all the rats in Experiment 1 being pair-fed isoenergetically, the body weight gain differed significantly between the four groups $(P<0 \cdot 005$, Table 2$)$. Rats fed the high fat diets (HSB, $\mathrm{HO}$ and $\mathrm{HF}$ ) had a significantly greater body weight gain than those fed the low fat diet (LSB). In the three high fat diet groups, the HO group showed the lowest body weight gain.

The HSB group showed a significantly higher relative weight of epididymal and retroperitoneal fat than the LSB rats $(P<0.05$ and $P<0.0001$, respectively), while the relative weights of the epididymal fat and retroperitoneal fat in the HF and $\mathrm{HO}$ groups were significantly lower than those in the HSB group, and were comparable with, or even lower than, those in the LSB group. In the $\mathrm{HO}$ group, the relative weight of the retroperitoneal fat was about half that in the LSB group. These data indicate that the OFO diet has a greater anti-adipogenic effect on the retroperitoneal fat depots than the fish oil diet.

\section{Adipose cell size}

Figure 1 shows the size distribution of adipocytes isolated from the epididymal (Fig. 1A-D) or retroperitoneal (Fig. 1E-H) fat pad of the rats in Experiment 1. In both the epididymal and retroperitoneal fat, the size distribution in the HO (Fig. 1C and G) and HF (Fig. 1D and H) groups showed a marked shift to the left compared with the HSB (Fig. 1B and F) and LSB (Fig. 1A and E) groups. There was no significant difference between the HSB and LSB groups in the mean diameter of the epididymal or retroperitoneal adipocytes (Table 3). However, the adipocyte diameter in the two fat depots was significantly smaller in the $\mathrm{HO}$ and $\mathrm{HF}$ groups than in the HSB group $(P<0.0001$ for both the epididymal and retroperitoneal fat). The adipocyte diameter in the HO group was only $60 \%$ that in the HSB group and $70-80 \%$ that in the HF group, and was even smaller than in the LSB group. 
Diameter $(\mu \mathrm{m})$
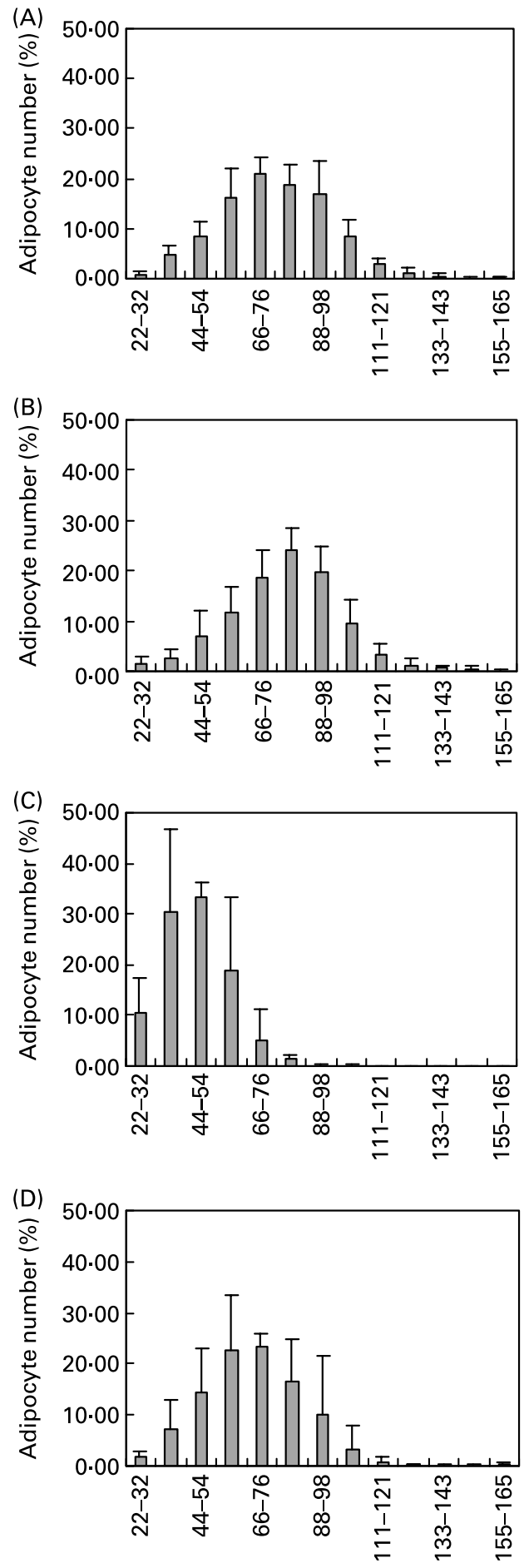

Diameter $(\mu \mathrm{m})$
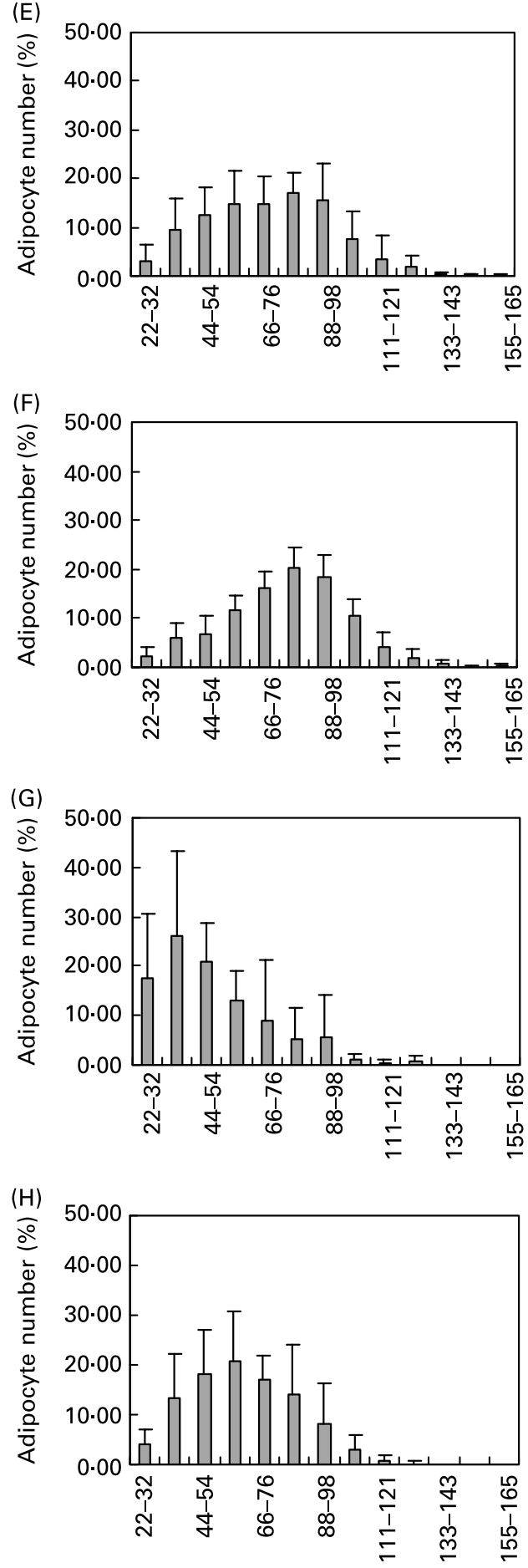

Diameter $(\mu \mathrm{m})$

Fig. 1. Diameter distribution curves of adipocytes isolated from the epididymal $(A-D)$ or retroperitoneal $(E-H)$ fat pads of rats fed a low fat diet containing $5 \mathrm{~g} / 100 \mathrm{~g}$ of fresh soybean oil (LSB; A and E) or a high fat diet containing $20 \mathrm{~g} / 100 \mathrm{~g}$ of fresh soybean oil (HSB; B and F), oxidised frying oil (HO; C and G) or fish oil (HF; D and H) for 6 weeks.

\section{Adipocyte lipid and DNA content}

Table 3 shows the lipid and DNA contents of the two fat depots in the rats in Experiment 1. In the epididymal fat, the HF group had a significantly lower lipid content (g/g tissue) than the other three groups $(P<0 \cdot 05)$. For both the epididymal and retroperitoneal fat pads, the change in the lipid content in the whole tissue (g/tissue) paralleled the change in the relative tissue weight. The 
Table 3. Cell diameter, lipid and DNA contents, and the lipid/DNA ratio in the epididymal or retroperitoneal fat pads of rats fed a low fat diet containing $5 \mathrm{~g} / 100 \mathrm{~g}$ of fresh soybean oil (LSB) or a high fat diet containing $20 \mathrm{~g} / 100 \mathrm{~g}$ of fresh soybean oil (HSB), oxidised frying oil (HO) or fish oil (HF) (Experiment 1)*

(Mean values and standard deviations for ten animals)

\begin{tabular}{|c|c|c|c|c|c|c|c|c|}
\hline & \multicolumn{2}{|c|}{ LSB } & \multicolumn{2}{|c|}{ HSB } & \multicolumn{2}{|c|}{$\mathrm{HO}$} & \multicolumn{2}{|c|}{$\mathrm{HF}$} \\
\hline & Mean & SD & Mean & SD & Mean & SD & Mean & SD \\
\hline \multicolumn{9}{|l|}{ Epididymal fat pad } \\
\hline Cell diameter $(\mu \mathrm{m})$ & $76^{\mathrm{ab}}$ & 5 & $80^{\mathrm{a}}$ & 7 & $47^{c}$ & 6 & $68^{\mathrm{b}}$ & 10 \\
\hline Lipid (g/g tissue) & $0.67^{\mathrm{a}}$ & 0.05 & $0.73^{\mathrm{a}}$ & 0.32 & $0.67^{\mathrm{a}}$ & 0.03 & $0.43^{\mathrm{b}}$ & 0.22 \\
\hline (g/tissue) & $1.97^{\mathrm{ab}}$ & 0.57 & $2 \cdot 76^{a}$ & 1.47 & $1.77^{\mathrm{ab}}$ & 0.49 & $1.52^{\mathrm{b}}$ & $1 \cdot 12$ \\
\hline DNA ( $\mu \mathrm{g} / \mathrm{g}$ tissue) & $555^{\mathrm{b}}$ & 194 & $584^{\mathrm{b}}$ & 304 & $857^{a}$ & 223 & $405^{b}$ & 122 \\
\hline ( $\mu \mathrm{g} /$ tissue $)$ & 1609 & 759 & 2073 & 844 & 2157 & 533 & 1379 & 726 \\
\hline Lipid/DNA (g/g) & $1322^{\mathrm{ab}}$ & 387 & $1470^{a}$ & 711 & $854^{\mathrm{b}}$ & 300 & $1053^{\mathrm{ab}}$ & 496 \\
\hline \multicolumn{9}{|l|}{ Retroperitoneal fat pad } \\
\hline Cell diameter $(\mu \mathrm{m})$ & $74^{\mathrm{ab}}$ & 13 & $79^{\mathrm{a}}$ & 6 & $51^{\mathrm{c}}$ & 15 & $63^{\mathrm{bc}}$ & 10 \\
\hline Lipid (g/g tissue) & 0.48 & 0.05 & 0.48 & 0.03 & 0.46 & 0.05 & 0.44 & 0.07 \\
\hline (g/tissue) & $1.59^{\mathrm{ab}}$ & 0.22 & $2 \cdot 07^{\mathrm{a}}$ & 0.71 & $0.61^{\mathrm{C}}$ & 0.48 & $1 \cdot 28^{\mathrm{b}}$ & 0.67 \\
\hline DNA ( $\mu \mathrm{g} / \mathrm{g}$ tissue) & $482^{\mathrm{b}}$ & 223 & $317^{\mathrm{b}}$ & 215 & $906^{\mathrm{a}}$ & 419 & $517^{\mathrm{b}}$ & 488 \\
\hline ( $\mu \mathrm{g} /$ tissue $)$ & 1562 & 594 & 1219 & 519 & 956 & 498 & 1404 & 1256 \\
\hline Lipid/DNA (g/g) & $1132^{b}$ & 384 & $2000^{a}$ & 1015 & $585^{\mathrm{b}}$ & 221 & $1275^{\mathrm{ab}}$ & 615 \\
\hline
\end{tabular}

*The significance of differences between the four groups was analysed by one-way ANOVA and Duncan's multiple range test. Mean values within a row with different superscript letters are significantly different $(P<0.05)$.

lipid contents of the epididymal fat in the HF group and of the retroperitoneal fat in the $\mathrm{HO}$ and $\mathrm{HF}$ groups were significantly smaller than in the HSB group $(P<0.05$ and $P<0.005$, respectively). The amount of DNA was used as a measure of the number of cells in the adipose tissue. The epididymal and retroperitoneal DNA contents ( $\mu \mathrm{g} / \mathrm{g}$ tissue) in the $\mathrm{HO}$ group were significantly higher than those in the other three groups $(P<0.01$ and $P<0.05$ for the epididymal and retroperitoneal fat, respectively). This result was in accordance with the observation that the $\mathrm{HO}$ group had the smallest adipose cells. However, there was no significant difference between the four groups in the whole tissue DNA content ( $\mu \mathrm{g} /$ tissue) in either the epididymal or retroperitoneal fat. Taken together, these results indicate that the reduction in fat mass in the OFO- and fish oil-fed rats was due to a reduction in cell size, rather than cell number. The lipid/DNA ratio was also calculated as an index of lipid content per cell. As shown in Table 3, the HSB group had the highest lipid/ DNA ratio, indicating hypertrophy of the adipocytes, especially in the retroperitoneal fat $(P<0 \cdot 01)$. In both the epididymal and retroperitoneal fat, the lipid/DNA ratio in the HO group was significantly smaller than in the HSB group, while that in the HF group was intermediate between the other two values.

\section{Glucose and leptin levels}

The fasting serum glucose and leptin levels in the rats in Experiment 1 are shown in Table 2. There was no significant difference in fasting glucose levels between the four groups at week 0 (data not shown). However, after 6 weeks of feeding, a tendency to hyperglycaemia was seen in the HO group, but not the HF group $(P=0 \cdot 0528)$. Levels of leptin, the well-known cytokine secreted by adipose tissue which shows a good correlation with fat mass (Maffei et al. 1995), were also measured. In accordance with the adiposity results, the HO and HSB groups showed the lowest and highest leptin level, respectively $(P<0 \cdot 05)$. Serum leptin levels were comparable in the HF and LSB groups.

\section{Glucose tolerance effect}

Experiment 2 compared glucose tolerance in rodents fed the LSB, HSB or HO diets. Table 4 shows that, in both rats and mice, the $\mathrm{HO}$ diet resulted in a significantly higher liver weight and a lower liver triacylglycerol content, as previously reported in rats (Chao et al. 2001, 2005). As in Experiment 1, in both rats and mice, the $\mathrm{HO}$ group showed a significantly lower body weight gain $(P<0.0001)$ and adipose tissue weight $(P<0 \cdot 0001)$ than the LSB and HSB groups (Table 4). However, higher fasting glucose levels were seen in the OFO-fed rats, but not in the mice fed the same diet. Fasting and feeding serum insulin levels were measured in the mice (Table 4). In both situations, the HO group had the lowest levels of the three groups $(P<0.005$ and $P<0.01$ at fasting and feeding status, respectively).

The OGTT results for the rats and mice are shown in Figs. 2 and 3 , respectively. In the rats, the area under the curve for blood glucose $\left(\mathrm{AUC}_{\mathrm{glu}}\right)$ over the $2 \mathrm{~h}$ after an oral glucose dose showed no difference between the LSB, HSB and HO groups at week 0 (data not shown). However, after being fed the experimental diets for 3 (Fig. 2A) or 9 (Fig. 2B) weeks, the $\mathrm{AUC}_{\mathrm{glu}}$ was significantly higher in the $\mathrm{HO}$ group than in the other two groups $(P<0.005$ and $P<0.0001$ at week 3 and week 9 , respectively).

After the mice were fed for 4 weeks, the $\mathrm{AUC}_{\text {glu }}$ over the $2 \mathrm{~h}$ after the oral glucose dose was higher in the $\mathrm{HO}$ group than in the other two groups $(P<0 \cdot 005 ;$ Fig. 3A). The change in insulin concentrations in the different groups of mice is shown in Fig. 3B, and the area under the curve for serum insulin $\left(\mathrm{AUC}_{\mathrm{ins}}\right)$ over the $90 \mathrm{~min}$ following the glucose dose was significantly lower in the $\mathrm{HO}$ group than in the other two groups $(P<0 \cdot 05)$.

\section{Discussion}

In this study, rats fed the OFO-containing diet (HO group) showed a significantly smaller tissue mass, cell size and 

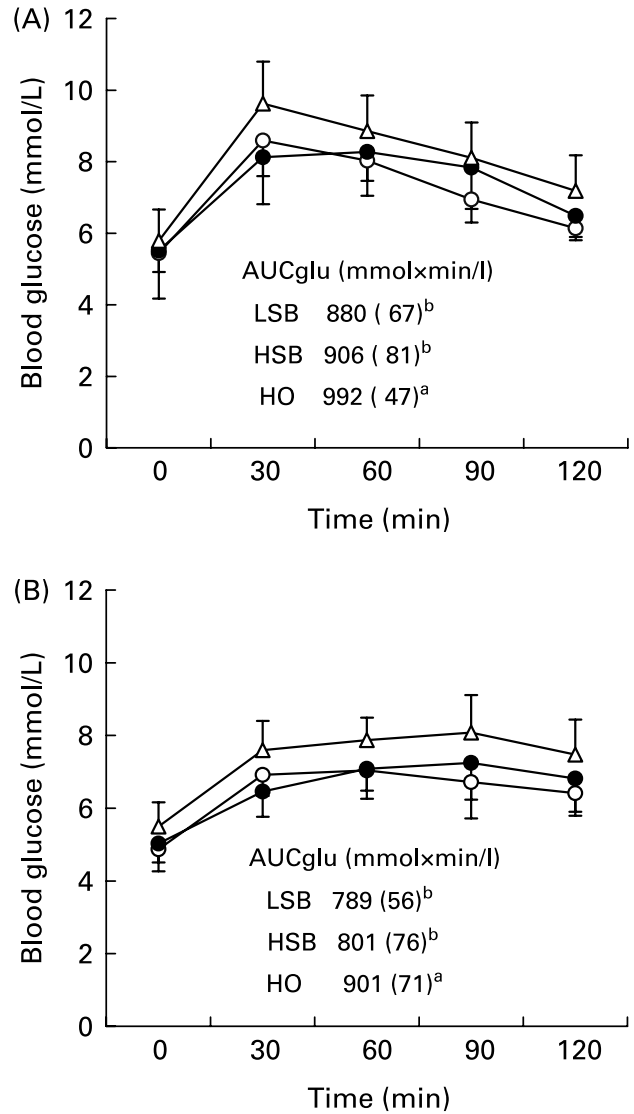

Fig. 2. Oral glucose tolerance tests performed on rats fed a low fat diet containing $5 \mathrm{~g} / 100 \mathrm{~g}$ of fresh soybean oil (LSB; O) or a high fat diet containing $20 \mathrm{~g} / 100 \mathrm{~g}$ of fresh soybean oil (HSB; $\bullet$ ) or oxidised frying oil (HO; $\Delta$ ) for 3 weeks (A) or 9 weeks (B). A glucose load (1.5 g/kg body weight) was given to rats after overnight fasting. At the indicated time points, tail blood was collected and blood glucose levels measured. The area under the curve for glucose $\left(\mathrm{AUC}_{\text {glu }} ; \mathrm{mmol} \times \mathrm{min} / \mathrm{l}\right)$ over $2 \mathrm{~h}$ was calculated and the results expressed as the mean (and SD), $n$ 10. The significance of the differences between the three groups was analysed by one-way ANOVA and Duncan's multiple range test. Values not sharing a superscript letter are significantly different $(P<0.05)$.

lipid/DNA ratio in the retroperitoneal fat pad, and serum leptin levels that were only $30-40 \%$ of those in the HSB group and half of those in the LSB group. These results show that dietary OFO has a greater anti-adiposity effect than similar levels of dietary fish oil. Surprisingly, the lowered adiposity in OFOfed rats did not result in better serum glucose control, as the OGTT showed that the OFO diet resulted in glucose intolerance in both rats and mice (Figs. 2 and 3). Though the animals in Experiment 2 were not pair-fed, it is unlikely that the lowered glucose tolerance in the HO group was due to lower energy intake, since the OGTT was performed at fasting status, and the caloric restriction should improve glucose tolerance (Okauchi et al. 1995; Park et al. 2005), not cause it to deteriorate. In addition, this inferior glucose tolerance is repeatedly observed in another batch of pair-fed mice (data not shown, study in progress).

The anti-adiposity effect of OFO could be partly attributed to the reduced fat absorption. During the deep-frying process, a series of reactions, including autoxidation, thermal oxidation, degradation, polymerisation and cyclisation, occur in the oil. 

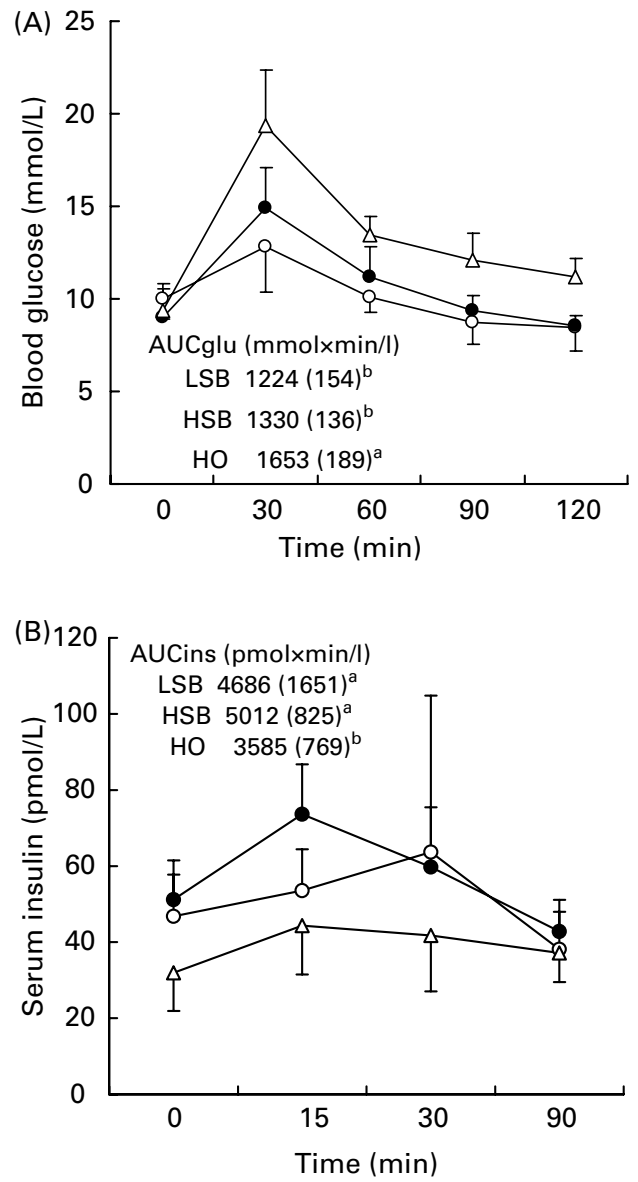

Fig. 3. Oral glucose tolerance tests performed on mice fed a low fat diet containing $5 \mathrm{~g} / 100 \mathrm{~g}$ of fresh soybean oil (LSB; $O$ ) or a high fat diet containing $20 \mathrm{~g} / 100 \mathrm{~g}$ of fresh soybean oil (HSB; $\bullet$ ) or oxidized frying oil ( $\mathrm{HO} ; \Delta)$ for 4 weeks. A glucose load (1.5 g/kg body weight) was given to mice after overnight fasting. At the indicated time points, tail blood was collected and blood glucose (A) and serum insulin (B) levels measured. The areas under the curve for blood glucose over $2 \mathrm{~h}\left(\mathrm{AUC}_{\text {glu }} ; \mathrm{mmol} \times \mathrm{min} / \mathrm{l}\right)$ and for serum insulin over $90 \mathrm{~min}\left(\mathrm{AUC}_{\text {ins }} ; \mathrm{pmol} \times \mathrm{min} / \mathrm{l}\right)$ were calculated and the results expressed as the mean (and SD), $n$ 10. The significance of differences between the three groups was analysed by one-way ANOVA and Duncan's multiple range test. Values not sharing a superscript letter are significantly different $(P<0.05)$.

Many reports have shown that digestion and absorption of the oxidised lipid are decreased, especially for the polymeric materials (Poling et al. 1970; González-Muñoz et al. 1998). In addition, hydrolysis of non-oxidised triacylglycerol by pancreatic lipase is also negatively affected by the presence of large amounts of thermoxidised compounds in the lumen (González-Muñoz et al. 1998). In our previous studies, a mild reduction (5-10\%) in fat absorption was observed in OFO-fed rats (Huang et al. 1988; Liu \& Huang, 1995). However, a greater reduction would be expected in this study since the OFO was fed at a higher level (20 v. $15 \%$ level for this study and the previous ones).

Since PPAR $\alpha$ activation can up-regulate the expression of genes involved in fatty acid oxidation (Schoonjans et al. 1996), it seems plausible that the anti-adiposity effect of OFO might also be related to activation of the PPAR $\alpha$ signalling pathway. A reduction in adiposity has been reported in rodents treated with PP, including fish oil and fibrates (Storlien et al. 1987; Parrish et al. 1990; Raclot et al. 1997; Baillie et al. 1999;
Guerre-Millo et al. 2000; Takahashi \& Ide, 2000; Mancini et al. 2001; Ye et al. 2001; Lee et al. 2002; Xie et al. 2002; Peyron-Caso et al. 2003). Like fish oil, dietary OFO has been shown to activate the PPAR $\alpha$ signalling pathway (Chao et al. 2001; Sulzle et al. 2004; Chao et al. 2005). Typical PP responses, including hepatomegaly, peroxisome proliferation, reduction in liver (and serum) lipids and upregulation of hepatic ACO and CYP4A gene expression, have been observed in rats fed high OFO and high fish oil diets (Chao et al. 2005). Based on the extent of peroxisome proliferation and upregulation of PPAR $\alpha$ target genes seen in the liver of rats in our previous study (Chao et al. 2005), the OFO we used appears to be a more potent PPAR $\alpha$ activator than fish oil. This may explain, at least in part, the greater anti-adipogenic effect of dietary OFO than that of fish oil seen in the present study, since increasing fatty acid catabolism in tissues (liver, muscle) theoretically limits lipid accretion in adipose tissue.

In rats fed a high fat diet, fish oil has been shown to decrease body fat deposition in a site-specific manner. Hypertrophy of visceral fat (epididymal and retroperitoneal), but not subcutaneous fat, is lower in rats fed a fish oil diet than in rats fed diets containing beef tallow or lard (Raclot et al. 1997; Peyron-Caso et al. 2003). In addition to increased fatty acid oxidation, enhanced lipolysis (Peyron-Caso et al. 2003), increased expression of uncoupling proteins and thermogenesis (Baillie et al. 1999; Takahashi \& Ide, 2000) have also been suggested to contribute to the anti-adiposity effect of fish oil. Moreover, an anti-adipogenic role of $n$-3 polyunsaturated fatty acids has also been proposed, since these were found to decrease levels of mRNAs for adipocyte markers in retroperitoneal fat (Raclot et al. 1997). Considering that dietary OFO: (1) reduced body fat accretion not only in visceral fats, but also in the subcutaneous fat (data not shown); and (2) fails to increase uncoupling protein-1 mRNA levels in brown adipose tissue in rats (unpublished results), the mechanism underlying the anti-adipogenic action of OFO might not be completely identical to that of the fish oil and fibrates.

It is generally accepted that a reduction in adipose mass can improve insulin sensitivity due to decreased circulating levels of adipose tissue-released mediators of insulin resistance. The beneficial effect of dietary fish oil on insulin action in a variety of diet-induced insulin-resistant rats is well documented (Storlien et al. 1987; Peyron-Caso et al. 2003). Similarly, specific PPAR $\alpha$ agonists (e.g. WY14643, ciprofibrate, fenofibrate or GW9578) not only reduce adiposity, but also improve insulin sensitivity in rodents with insulin resistance, either induced by diet (Guerre-Millo et al. 2000; Mancini et al. 2001; Ye et al. 2001) or spontaneous (Lee et al. 2002). In contrast, treatment of normal chow diet-fed mice with the potent $\mathrm{PP}$, perfluoro-ocatanoic acid, produces a dramatic decrease in adipose tissue mass, accompanied by increased serum levels of tumour necrosis factor- $\alpha$ (Xie et al. 2002), leading to the speculation that perfluoro-ocatanoic acid-treated mice might have attenuated insulin sensitivity.

In this study, OFO was shown to be a potent anti-adiposity agent; however, a compromised glucose tolerance in OFO-fed rodents was also observed. This situation is somewhat similar to that in trans-10, cis-12 conjugated linoleic acid (CLA)-fed mice (Tsuboyama-Kasaoka et al. 2000; Roche et al. 2002). CLA consists of a group of positional and geometric isomers of conjugated dienoic derivatives of linoleic acid, 
mainly cis-9, trans -11 and trans-10, cis-12 isomers, naturally found in beef, dairy products and hydrogenated vegetable oils. There are reports indicating that trans-10, cis-12 CLA, with the most anti-adipogenic potential, produces lipodystrophy diabetes in C57BL/6J mice and ob/ob mice (TsuboyamaKasaoka et al. 2000; Roche et al. 2002). However, many differences exist between CLA- and OFO-fed rodents. Most strikingly, hypoinsulinaemia rather than hyperinsulinaemia was seen in the OFO-fed rodents (Table 4 and Fig. 3B), suggesting that the glucose intolerance is mediated by insulin deficiency, rather than peripheral insulin resistance as happens in CLA-fed mice. The decreased circulating insulin levels may decrease glucose uptake by skeletal muscle and adipose tissue and impair glucose tolerance.

The mechanism of the hypoinsulinaemia caused by high OFO consumption may involve impaired insulin secretion due to impaired function of pancreatic beta cells or increased liver extraction of insulin from the portal blood. It is known that OFO feeding induced higher oxidative stress (Izaki et al. 1984; Brandsch \& Eder, 2004), which may result in oxidative damage to the pancreas. Reactive oxygen species were proved to play a causal role in multiple forms of insulin resistance induced by tumour necrosis factor- $\alpha$ or dexamethasone (Houstis et al. 2006). In addition, we could not exclude the possibility that the metabolic alteration in OFO-fed rats might partially be related to a compromised vitamin E status, since most of the vitamin $\mathrm{E}$ in the oil is destroyed during the frying process and the absorption and retention of this vitamin in tissues is reduced in rats fed a frying oil diet (Liu \& Huang, 1995, 1996). Recently, Oshima et al. (2006) showed that the increased prostaglandin $\mathrm{E}_{2}$ expression in the islets resulted in the destruction of pancreatic beta cells. Since significantly higher prostaglandin $E_{2}$ metabolites in plasma and urine of OFO-fed rats have been observed in our previous studies (Huang, 2003), whether the glucose intolerance observed in the OFO-fed rodents is associated with an altered prostaglandin metabolism is under investigation.

In this study, dietary OFO was shown to have a greater antiadiposity effect than fish oil. Unexpectedly, the anti-adiposity effect of the high OFO diet was associated with impaired glucose tolerance in rats and mice, as shown by an increased $\mathrm{AUC}_{\mathrm{glu}}$ and decreased $\mathrm{AUC}_{\mathrm{ins}}$ in the OGTT. Fried foods are popular with consumers worldwide. The OFO used in our experiments was prepared under realistic cooking practices, but in an abusive condition. The quality and oxidative level of frying oil may not be well controlled, especially in developing countries. The reduced adiposity and impaired glucose tolerance seen in OFO-fed rodents is reminiscent of lean-type diabetes mellitus, which is prevalent in developing countries. Until now, we knew very little about the effects of dietary OFO consumption on glucose/insulin metabolism. Now that we know that high OFO consumption may compromise glucose tolerance, the effect and underlying mechanism of dietary OFO on adipogenesis and glucose metabolism merit further study.

\section{Acknowledgements}

The work was supported by grants from the National Science Council (NSC92-2320-B-039-027) and China Medical University (CMU93-NT-02), Taiwan.

\section{References}

Baillie RA, Takada R, Nakamura M \& Clarke SD (1999) Coordinate induction of peroxisomal acyl-CoA oxidase and UCP-3 by dietary fish oil: a mechanism for decreased body fat deposition. Prostaglandins Leukot Essent Fatty Acids 60, 351-356.

Brandsch C \& Eder K (2004) Effects of peroxidation products in thermoxidised dietary oil in female rats during rearing, pregnancy and lactation on their reproductive performance and the antioxidative status of their offspring. Br J Nutr 92, 267-275.

Chao PM, Chao CY, Lin FJ \& Huang C (2001) Oxidized frying oil up-regulates hepatic acyl-CoA oxidase and cytochrome P450 4 A1 genes in rats and activates PPARalpha. J Nutr 131, 3166-3174.

Chao PM, Yang MF, Tseng YN, Chang KM, Lu KS \& Huang C (2005) Peroxisome proliferation in liver of rats fed oxidized frying oil. J Nutr Sci Vitaminol 51, 361-368.

Das S (1999) Low bodyweight type 2 diabetes mellitus. J Nutr Environ Med 9, 229-239.

Despres JP (2006) Intra-abdominal obesity: an untreated risk factor for type 2 diabetes and cardiovascular disease. $J$ Endocrinol Invest $\mathbf{2 9}, 77 \mathrm{~S}-82 \mathrm{~S}$.

Folch J, Lees M \& Sloane Stanley GH (1957) A simple method for the isolation and purification of total lipids from animal tissues. J Biol Chem 226, 497-509.

González-Muñoz MJ, Bastida S \& Sánchez-Muniz FJ (1998) Shortterm in vivo digestibility of triglyceride polymers, dimers, and monomers of thermoxidized palm olein used in deep-frying. J Agric Food Chem 46, 5188-5193.

Guerre-Millo M, Gervois P, Raspe E, et al. (2000) Peroxisome proliferator-activated receptor alpha activators improve insulin sensitivity and reduce adiposity. J Biol Chem 275, 16638-16642.

Hirsch J \& Gallian E (1968) Methods for the determination of adipose cell size in man and animals. J Lipid Res 9, 110-119.

Houstis N, Rosen ED \& Lander ES (2006) Reactive oxygen species have a causal role in multiple forms of insulin resistance. Nature 440, 944-948.

Huang C (2003) Prostaglandin formation as affected by dietary frying oil and other food components. In Essential Fatty Acids and Eicosanoids: Invited Papers from the Fifth International Congress, pp. 132-140 Urbana, IL: AOCS Press.

Huang C, Cheung NS \& Lu VR (1988) Effects of deteriorated frying oil and dietary protein levels on liver microsomal enzymes in rats. $J$ Am Oil Chem Soc 65, 1796-1803.

Izaki Y, Yoshikawa S \& Uchiyama M (1984) Effect of ingestion of thermally oxidized frying oil on peroxidative criteria in rats. Lipids 19, 324-331.

Lee HJ, Choi SS, Park MK, et al. (2002) Fenofibrate lowers abdominal and skeletal adiposity and improves insulin sensitivity in OLETF rats. Biochem Biophys Res Commun 296, 293-299.

Liu JF \& Huang CJ (1995) Tissue alpha-tocopherol retention in male rats is compromised by feeding diets containing oxidized frying oil. J Nutr 125, 3071-3080.

Liu JF \& Huang CJ (1996) Dietary oxidized frying oil enhances tissue alpha-tocopherol depletion and radioisotope tracer excretion in vitamin E-deficient rats. $J$ Nutr 126, 2227-2235.

Maffei M, Halaas J, Ravussin E, et al. (1995) Leptin levels in human and rodent: measurement of plasma leptin and ob RNA in obese and weight-reduced subjects. Nat Med 1, 1155-1161.

Mancini FP, Lanni A, Sabatino L, Moreno M, Giannino A, Contaldo F, Colantuoni V \& Goglia F (2001) Fenofibrate prevents and reduces body weight gain and adiposity in diet-induced obese rats. FEBS Lett 491, 154-158.

Okauchi N, Mizuno A, Yoshimoto S, Zhu M, Sano T \& Shima K (1995) Is caloric restriction effective in preventing diabetes mellitus in the Otsuka Long Evans Tokushima fatty rat, a model of spontaneous non-insulin-dependent diabetes mellitus? Diabetes Res Clin Pract 27, 97-106. 
Oshima H, Taketo MM \& Oshima M (2006) Destruction of pancreatic $\beta$-cells by transgenic induction of prostaglandin E2 in the islets. J Biol Chem 281, 29330-29336.

Park SY, Choi GH, Choi HI, Ryu J, Jung CY \& Lee W (2005) Calorie restriction improves whole-body glucose disposal and insulin resistance in association with the increased adipocyte-specific GLUT4 expression in Otsuka Long-Evans Tokushima fatty rats. Arch Biochem Biophys 436, 276-284.

Parrish CC, Pathy DA \& Angel A (1990) Dietary fish oils limit adipose tissue hypertrophy in rats. Metabolism 39, 217-219.

Peyron-Caso E, Quignard-Boulange A, Laromiguiere M, FeingKwong-Chan S, Veronese A, Ardouin B, Slama G \& Rizkalla SW (2003) Dietary fish oil increases lipid mobilization but does not decrease lipid storage-related enzyme activities in adipose tissue of insulin-resistant, sucrose-fed rats. J Nutr 133, 2239-2243.

Poling CE, Eagle E, Rice EE, Durand AM \& Fisher M (1970) Longterm responses of rats to heat-treated dietary fats. IV. Weight gains, food and energy efficiencies, longevity and histopathology. Lipids $\mathbf{5}, 128-136$.

Raclot T, Groscolas R, Langin D \& Ferre P (1997) Site-specific regulation of gene expression by $n-3$ polyunsaturated fatty acids in rat white adipose tissues. J Lipid Res 38, 1963-1972.

Roche HM, Noone E, Sewter C, Mc Bennett S, Savage D, Gibney MJ, O'Rahilly S \& Vidal-Puig AJ (2002) Isomer-dependent metabolic effects of conjugated linoleic acid: insights from molecular markers sterol regulatory element-binding protein-1c and LXRalpha. Diabetes 51, 2037-2044.
Saha SK, Moriya M, Ohinata H \& Kuroshima A (1994) Lipid interference with fluorometric assay of DNA in adipose tissues under various conditions. Jpn J Physiol 44, 421-431.

Schoonjans K, Staels B \& Auwerx J (1996) Role of the peroxisome proliferator-activated receptor (PPAR) in mediating the effects of fibrates and fatty acids on gene expression. J Lipid Res 37, 907-925.

Storlien LH, Kraegen EW, Chisholm DJ, Ford GL, Bruce DG \& Pascoe WS (1987) Fish oil prevents insulin resistance induced by high-fat feeding in rats. Science 237, 885-888.

Sulzle A, Hirche F \& Eder K (2004) Thermally oxidized dietary fat upregulates the expression of target genes of PPAR alpha in rat liver. J Nutr 134, 1375-1383.

Takahashi Y \& Ide T (2000) Dietary $n-3$ fatty acids affect mRNA level of brown adipose tissue uncoupling protein 1 , and white adipose tissue leptin and glucose transporter 4 in the rat. Br J Nutr $\mathbf{8 4}$, $175-184$.

Tsuboyama-Kasaoka N, Takahashi M, Tanemura K, Kim HJ, Tange T, Okuyama H, Kasai M, Ikemoto S \& Ezaki O (2000) Conjugated linoleic acid supplementation reduces adipose tissue by apoptosis and develops lipodystrophy in mice. Diabetes 49, 1534-1542.

Xie Y, Yang Q, Nelson BD \& DePierre JW (2002) Characterization of the adipose tissue atrophy induced by peroxisome proliferators in mice. Lipids 37, 139-146.

Ye JM, Doyle PJ, Iglesias MA, Watson DG, Cooney GJ \& Kraegen EW (2001) Peroxisome proliferator-activated receptor (PPAR)alpha activation lowers muscle lipids and improves insulin sensitivity in high fat-fed rats: comparison with PPAR-gamma activation. Diabetes 50, 411-417. 